\title{
Organizational Alignment
}

Inge Angevaare (Netherlands Coalition for Digital Preservation)

Michelle Gallinger (Library of Congress)

Martha Anderson (Library of Congress)

David Giaretta (Alliance for Permanent Access)

Martin Halbert (University of North Texas)

\begin{abstract}
Digital preservation is not just a technical issue: there are also many organizational implications that must be addressed. This essay first identifies requirements that distinguish successful from unsuccessful modes of organizing digital preservation and long-term access, then presents a series of case studies that examine examples of addressing those requirements. These case studies all represent cooperative or collaborative approaches, in keeping with current research that demonstrates that institutions must share the financial and organizational burden of digital preservation in order to make it cost-effective. The case studies are drawn both from Europe and the United States, and include both single repository solutions and distributed preservation networks. A special role is played by so-called "enabling institutions"-national or regional initiatives established to raise awareness of the issues and promote cooperation in research and development. The essay concludes by considering possible areas for community alignment and next steps.
\end{abstract}

\section{Introduction}

The challenge of preserving digital objects is as much an organizational issue as it is a technical one. Both the possibilities and the special requirements of digital objects have their impact not just on storage systems, but on entire organizations, as was clearly described in the Open Archival Information System (OAIS) model. ${ }^{1}$ Moreover, the emergence and explosive growth of the

\footnotetext{
${ }^{1}$ (ISO) Reference Model for an Open Archival Information System (OAIS). "An OAIS is an archive, consisting of an organization of people and systems, that has accepted the responsibility to preserve information and make it available for a Designated Community. It meets a set of such responsibilities as defined in this document, and this allows an OAIS archive to be distinguished from other uses of the term 'archive.' ... The information being maintained has been deemed to need Long Term Preservation, even if the OAIS itself is not permanent. Long Term is long enough to be concerned with the impacts of changing technologies, including
} 
Internet have fundamentally changed the environment in which memory institutions operate.

Laura Campbell of the US Library of Congress has summarized some of the major changes between the analog information space and the digital information space as follows: ${ }^{2}$

\begin{tabular}{|l|l|l|}
\hline Then (Analog) & v. & Now (Digital) \\
\hline Atoms & v. & Bits \\
\hline High level of curation & v. & Bulk download \\
\hline Ownership & v. & Shared access \\
\hline Consumers & v. & Discoverers \\
\hline Watching & v. & Creating \\
\hline Institutional identity & v. & Loose collaboration \\
\hline Push & v. & Pull \\
\hline Systematic planning & v. & Fluid cooperation \\
\hline Closed platforms & v. & Open platforms \\
\hline Expert vetting & v. & Cognitive surplus \\
\hline
\end{tabular}

Figure 1. Differences between the analog information space and the digital information space (Laura Campbell, 2011).

This is to say, digital information is capable of flowing freely across boundaries between institutions, sectors, and countries. Today's users have come to expect to access the information they need 24/7 and wherever they find themselves, preferably on platforms that bring the content together from any number of institutions. Moreover, individuals have become co-creators of digital information at a large scale, thereby disrupting existing chains of custody and existing preservation regimes.

All of this means that to secure access to our digital heritage in the long term, new ways of organizing the work are needed at a scale never seen before and which, indeed, stretches the boundaries of imagination. Organizational alignment strategies are needed on two related levels - first, to organize our collections and our workflows according to common standards to facilitate long-term

support for new media and data formats, or with a changing user community. Long Term may extend indefinitely."

http://public.ccsds.org/publications/RefModel.aspx (last accessed 04-10-2012).

2 Laura Campbell, "Exploring what we can do together: strategic alignments for international collaboration," Keynote at the ANADP Conference, May 2011. Slides at http://www.educopia.org/sites/default/files/keynote1 campbell.pdf (last accessed 04-10-2012). 
curation and preservation, and second, to optimize our work for collaboration and provide organizational models for coordinating our efforts to ensure long-term access.

Some institutions and sectors are adapting more quickly to the new situation than others. Scientific communities with a strong dependency on longitudinal data (e.g., climate data, sociology) have been early adopters of the new technology and have numbered among the first to develop long-term preservation systems and work processes in tune with the digital reality. In other sectors, the uptake has been a lot slower and organizational principles based on the analog world still prevail.

This essay first identifies requirements that distinguish successful from unsuccessful modes of organizing digital preservation and long-term access, then presents a series of case studies that examine examples of addressing those requirements. It concludes by considering possible areas for community alignment and next steps. In keeping with the theme of the volume, this essay focuses on organizational cooperation and collaboration between institutions rather than on internal organizational issues.

\section{Digital Preservation Requirements}

The authors of this essay have identified the following six characteristics as requirements for successful digital preservation endeavors:

1. Digital preservation requires long-term commitment;

2. Digital preservation is most cost-efficient at scale;

3. Digital preservation requires effective interaction between producers, digital archives, and users;

4. Digital preservation benefits from the exploitation of commonalities rather than a focus on uniqueness;

5. Digital preservation initiatives must make a large enough impact right now to make the case to funders and society at large for sustaining these efforts;

6. Digital preservation requires a division of labor from a digital perspective.

Each of these characteristics is defined and reviewed below to determine the role it plays in successful digital preservation activities. These characteristics are then applied to evaluate a series of organizational case studies. 


\section{Digital preservation requires long-term commitment}

This is a key factor in organizing digital preservation that sets it firmly apart from other digital developments such as Wikipedia, crowdsourcing, etc., which are largely based on spontaneous groupings of people and organizations. As valuable as these movements are in producing content and/or metadata, they do not have the robustness to secure the type of continuous lifecycle management that digital objects require. ${ }^{3}$ Any disruptions of such lifecycle management can lead to irreparable loss of data and must be avoided. In principle, long-standing institutions such as national libraries, national archives, and institutional repositories with an express mandate for long-term preservation are better positioned to provide long-term preservation - but even those institutions are not risk-free. It is therefore important that one think and act in terms of a chain of preservation (also known as a chain of custody) in which each custodial organization plans for its own demise and succession planning is a key effort.

\section{Digital preservation is most cost-efficient at scale}

Preserving and providing access to digital objects in the long term is an activity that involves a robust infrastructure that is run by knowledgeable staff members who are continually educated in response to technological progress. Few organizations have the means to support such an infrastructure by themselves. Especially smaller, underfunded institutions are vulnerable in this sense. Forging alliances with other institutions is a means to reach the economies of scale that make digital preservation more costefficient. $^{4}$

\section{Digital preservation requires effective interaction between producers, archives, and users}

As noted above, digital objects require active management throughout their lifecycle and that lifecycle starts at the production stage, where many decisions are made that affect a digital object's long-term prospects. The Dutch national digital preservation

\footnotetext{
${ }^{3}$ See, e.g., the DCC lifecycle model at http://www.dcc.ac.uk/resources/curationlifecycle-model (last accessed 04-24-2012).

${ }_{4}^{4}$ For an inventory of the economic issues surrounding digital preservation and a summary of recent research, see Sustaining Economics for a Digital Planet: Ensuring Long-term Access to Digital Information, Final Report of the Blue Ribbon Task Force on Sustainable Digital Preservation and Access, February 2010, http://brtf.sdsc.edu/ (last accessed 04-24-2012).
} 
survey, ${ }^{5}$ among others, concluded that lack of alignment between producers of digital information and the archives that might preserve them is one of the major reasons for digital information being lost. Once the so-called chain of preservation is broken, it either cannot be repaired or repair can only occur at great expense. Therefore, digital preservation initiatives must seek to bridge the gap between producers and archives. The OAIS model itself has described the need for interaction between the digital archive and users, the designated community. ${ }^{6}$

It must be noted here that effective interaction between producers and archives cannot always be achieved. Large quantities of information that are created and uploaded to the Internet by private individuals still elude a structured work flow between creator and archive.

\section{Digital preservation requires exploitation of commonalities rather than a focus on uniqueness}

This requirement is related to the one about scale, but it goes a level deeper than issues of economy. The digital information space is an interconnected information space where smooth interaction between collections is instrumental in securing access for many users all over the world. Some examples include the standardization of file formats and interaction protocols and the level of detail in required metadata schemas. Each domain that joins the digital community has a tendency to believe that its requirements are special, more challenging, or even unique, making it difficult to see digital content commonalties that cut across digital content wherever it occurs.

\section{Digital preservation initiatives must make a large enough impact in the present to make the case for digital preservation vis-à-vis funders and society at large}

The report of the Blue Ribbon Task Force (2010) describes in detail how difficult it is to attract funding for digital preservation, chiefly because the benefits are long-term and the direct relationship between investment and benefit is not clear (the so-

\footnotetext{
${ }^{5}$ NCDD (Netherlands Coalition for Digital Preservation), A Future for our Digital Memory: Permanent access to information in the Netherlands, English summary, http://www.ncdd.nl/en/documents/Englishsummary 000.pdf (last accessed 04-242012).

${ }^{6}$ For more in-depth analysis of the role of the designated community in the OAIS model, see, a.o., David Giaretta, Advanced Digital Preservation, Springer 2011, chapters 1-3.
} 
called free rider problem). Yet, it is evident that in order to secure funding, the digital preservation community must develop convincing arguments and find the words to make the case for digital preservation. As long-term benefits hardly ever convince politicians and other power-holders, more direct benefits must be shown and the argument must be made by a large enough group of stakeholders to make their voices heard.

\section{Digital preservation requires a division of labor from a digital perspective}

Practices developed for the long-term management of analog content need to be adjusted to adapt to digital content. In the analog era, information was managed and often owned locally. The digital era has opened up new possibilities to provide access to objects stored and/or preserved elsewhere. In addition, dividing lines between domains and sectors are blurring and born-digital categories of information have emerged that have not yet been incorporated into memory institutions' collection profiles. Roles and responsibilities with regard to these types of content have yet to be defined.

Reviewing all the requirements listed above, it is reasonable to conclude that there are strong reasons for seeking cooperation and collaboration in digital preservation, but collaboration between whom, at what level, and under what conditions?

\section{Types of Cooperation and Collaboration in Digital Preservation}

Cooperative efforts in digital preservation come in many shapes and sizes. As described in Beyond the Silos of the LAMs (Zorich, Waibel, and Erway, 2008) actual collaboration does not come about easily, and in quite a few countries enabling organizations have been established to do advocacy work, promote sharing of knowledge, and, more generally, bring different parties around one table to discuss possibilities for cooperation. Typically, these enabling organizations represent a gradual approach to cooperation and collaboration. They include the National Digital Information Infrastructure and Preservation Program (NDIIPP, US), the Digital Preservation Coalition (DPC, UK and Ireland), the Netherlands Coalition for Digital Preservation (NCDD, Netherlands), nestor (Germany), the Alliance for Permanent Access (APA, Europe), the International Internet Preservation Consortium (IIPC, worldwide), the Open Planets Foundation 
(OPF, Europe), and PrestoCentre (Europe, audiovisual). All of these organizations will be described in more detail below.

Enabling organizations cannot themselves embody all of the requirements listed above, as they are not legal entities that are responsible for preserving digital collections. However, they can and do encourage the projects and partnerships they facilitate to address these requirements as grounded in community standards and practice.

Cooperation in projects or within enabling organizations evolves into collaboration when partners actually start sharing the burden of digital preservation by taking custody of third parties' digital collections.

\section{Case Studies}

This section takes a closer look at a few of the organizations mentioned in the previous section. The case studies include two enabling organizations, NDIIPP and APA, as well as several national and international preservation organizations that include OPF, PrestoCentre, LOCKSS, MetaArchive, Chronopolis, and DuraCloud. The coverage is not intended to be exhaustive but illustrative.

\section{NDIIPP}

Since 2000, the US National Digital Information Infrastructure and Preservation Program (NDIIPP) has established, strengthened and expanded a network of digital preservation partners. The charter for NDIIPP called for collaboration between private and public organizations. ${ }^{7}$ The results include practical experience in defining roles and responsibilities and building trust across a distributed preservation network. By successfully leveraging the strengths of a variety of partners, the network has proven flexible in the face of technological unpredictability, economic downturn, and the exponential growth of digital material. More than sixty sponsored projects demonstrated the value of collaboration around common work and values. The 2010 founding of a more structured network, the National Digital Stewardship Alliance (NDSA), grew out of this collective experience and out of the desire for program-based, long-term collaboration.

The NDIIPP Program's strategy of collaboration led to significant outcomes for the six requirements for digital

\footnotetext{
${ }^{7}$ Public Law 106-554 2001, Consolidated Appropriations Act.
} 
preservation stated in this chapter. To sustain commitment to digital preservation, the NDIPP program moved from sponsoring special projects to founding and supporting an ongoing national alliance of partners to collect, preserve, and make available significant digital content for current and future generations. The shift from special project to ongoing program has also been evident in many of the institutions within the collaborative network. The NDIIPP-sponsored projects fostered partners' long-term commitment to digital preservation by demonstrating concrete examples of the value of preserving digital materials to stakeholders. In addition to catalyzing a national commitment to digital preservation, NDIIPP leverages lessons learned through the partners to support preservation activities within the Library of Congress's traditional preservation units via development of guidelines, policy, software, tools, assistance with content acquisition, and educational activities.

A major tenet of NDIIPP is that collaboration is needed to achieve digital preservation results at scale. This approach leverages the wide variety of experience and resources that institutions have to offer. Sharing knowledge and services, such as storage and data management tools, amongst institutions allows the partners to maximize local resources while contributing to the digital preservation community. NDIIPP has sponsored innovation projects, investing in tools, research, standards, and other developments for the benefit of the partner network.

The heterogeneity of the collaborative network is experienced as an asset; it provides resilience in the face of changing technical, policy, and economic environments. The Program has served to catalyze interactions between producers, consumers, archivists, and curators of diverse digital information. In some cases, working directly with the Library of Congress, communities have been able to tackle issues that have challenged the individual institutions. One example is the Preserving Creative America initiative to support the preservation of a wide range of works created by photographers, and music and motion picture producers. ${ }^{8}$ Diverse business enterprises were able to find common ground on metadata, tools, and outreach to creators.

The Program has also been able to encourage stakeholders across diverse domains to work together, even though they are confronted by unique content, business, and technology challenges. Early in the Program, common concerns and issues were identified

\footnotetext{
${ }^{8}$ See the press release from the Library of Congress for additional information: http://www.loc.gov/today/pr/2007/07-156.html (last accessed 07-12-2012).
} 
including rights management, technical environments, and economic sustainability. To this day, storage has been an area of common interest. The annual Designing Storage Architectures for Digital Preservation meeting ${ }^{9}$ provides opportunities for the commercial storage community and the preservation community to discuss their needs and activities. Together they address key data storage issues, including: data integrity, compression, deduplication practices, processing and analytics of large data sets, format and technical migration, and more. Across time each community has worked on appropriate standards and improved practices. This exchange exemplifies the importance of consistent communication between different groups over time.

A major result of the NDIIPP Program has been to clarify roles in order to successfully distribute digital preservation tasks throughout the network. ${ }^{10}$ The collaborative approach recognizes that each institution brings special abilities and expertise to the network.

There are four categories of roles in the network: Committed Content Custodians are institutions with a stewardship mission; Communities of Practice include standards, policy, and guidelines working groups; Services include tools developers, infrastructure, legal, or other business service providers; Capacity Building includes educational and funding institutions. A single institution can serve in one or more of these roles depending upon resources and expertise. Not every institution is going to be good at every stage of the digital preservation lifecycle, but by collaborating, we ensure that all stages can be adequately handled

The NDIIPP partner network has demonstrated the value of digital preservation for a number of years. Evidence of the impact can be seen in the dissemination of US public policies on digital data and records management and in the growing adoption of digital preservation practices across stewardship institutions. There is also growing public awareness of digital preservation. The most popular section of digitalpreservation.gov ${ }^{11}$ highlights the importance of personal digital preservation by providing the general public with information on how to manage their digital photos, music, videos, and other personal data.

\footnotetext{
${ }^{9}$ See http://www.digitalpreservation.gov/meetings/storage11.html (last accessed 0424-2012).

${ }^{10}$ Martha Anderson, "Evolving a Network of Networks," The International Journal of Digital Curation, Issue 1, vol 3, 2008. www.ijdc.net/index.php/ijdc/article/download/59/38 (last accessed 04-24-2012).

${ }^{11}$ See http://www.digitalpreservation.gov/personalarchiving/ (last accessed 04-242012).
} 
The NDIIPP Program, working with over 245 organizations from 48 states and 26 countries, continues to bring together diverse stakeholders to share expertise and build common understanding. By approaching digital preservation collaboratively, the Program, through the National Digital Stewardship Alliance, is able "to avoid duplicate work, build a community of practice, develop new preservation strategies, flexibly respond to a changing economic landscape, and build relationships to increase capacity to manage content beyond institutional boundaries." 12

\section{The Alliance for Permanent Access $(A P A)^{13}$}

In 2005, a group of mostly European institutions involved in scholarly communications and scientific research came together in order to pool their resources and work together on digital preservation by creating the Alliance for Permanent Access (APA). The APA is a not-for-profit membership organization that includes large international and national science institutions, national libraries, funders, publishers, and national coalitions, and is now open to all interested in digital preservation including public and commercial organizations and individuals from across the world. A key sentence in the APA's strategic plan was: "The creation of a sustainable infrastructure to support permanent access to the digital scientific record raises many technical, organizational, economic, legal, and social issues."14 The establishment of the APA was welcomed by the European Commission, which since 2001, had taken an active interest in developing a digital agenda for Europe, and which has funded a considerable number of Europe-wide research and development projects in the area of digital preservation.

One of the key activities for the Alliance is to act as an umbrella institution putting together consortia to bid to the EU for digital preservation projects. These projects take their lead from a project that preceded the APA: Cultural, Artistic, and Scientific knowledge for Preservation, Access, and Retrieval (CASPAR),

\footnotetext{
${ }^{12}$ See National Digital Stewardship Alliance Value Statement, www.digitalpreservation.gov/ndsa (last accessed 04-24-2012).

${ }_{13}$ Further details are available at the APA website http://www.alliancepermanentaccess.org (last accessed 04-24-2012). Details of the projects CASPAR, PARSE.Insight, APARSEN, ODE, SCIDIP-ES are available at http://www.alliancepermanentaccess.org/index.php/community/current-projects/ (last accessed 07-12-2012).

${ }^{14}$ See APA: http://www.alliancepermanentaccess.org. (last accessed 04-24-2012).
} 
part funded by the EU. ${ }^{15}$ CASPAR was based on the realization that the "migrate or emulate" mantra that is often heard, while perhaps adequate for documents and images, was not adequate for digitally encoded information in general, especially more complicated objects, and those that cannot be, for example, simply rendered on a screen; the mantra must be extended at least to "migrate, emulate or describe". Amongst other things CASPAR produced prototypes for discipline-independent infrastructure components which could help preserve any type of data, as shown by the many examples used in the testbeds; ${ }^{16}$ the preservation effectiveness was checked by what might be termed "accelerated lifetime" scenarios, with simulated changes in hardware, software, environment, and tacit knowledge, verified by the "designated community" from the OAIS model.

The first of the projects under the APA umbrella was PARSE.Insight. ${ }^{17}$ This initiative gathered fundamental information about what people actually think and do about digital preservation through a set of surveys and case studies of researchers, data managers, and publishers. There were thousands of responses from around the world and from a great variety of disciplines. Given this substantial number of respondents, there was surprising agreement about key threats to digital preservation. Based on these results, the PARSE.Insight roadmap identified the need for a relatively modest and overarching operational infrastructure.

The results also recognized the need to combine all types of digitally encoded information in future, e.g., as described in Riding the Wave report by the European High Level Expert Group on Scientific Data. ${ }^{18}$ That report draws attention to the future value and benefits arising from keeping our digitally encoded intellectual capital. The same arguments apply right now and must be deployed to justify resources used for preservation.

APARSEN is another EU project that started in 2011. ${ }^{19}$ The project envisions a large Network of Excellence that aims to

\footnotetext{
${ }^{15}$ The project website is available at www.casparpreserves.eu (last accessed 04-242012).

${ }^{16}$ CASPAR Validation/Evaluation Report, available at http://www.alliancepermanentaccess.org/filestore/CASPARdeliverables/CASPAR-4104-RP-0101-1 0.pdf (last accessed 04-24-2012).

${ }^{17}$ The project website is available at http://www.parse-insight.eu/ (last accessed 0424-2012).

${ }^{18}$ Available at http://cordis.europa.eu/fp $7 /$ ict/e-infrastructure/docs/hlg-sdireport.pdf with press release http://ec.europa.eu/information_society/newsroom/cf/itemlongdetail.cfm?item_id $=6204$ (last accessed 04-24-2012).

${ }^{19}$ The project website is available at www.aparsen.eu (last accessed 04-24-2012).
} 
reduce fragmentation in digital preservation efforts by bringing together research in digital preservation across Europe-academia, industry, vendors, and large science laboratories, as well as libraries - to reach a common vision for research in digital preservation. This is not to say that some tools or techniques will be labeled as wrong. Instead the project expects to provide an overall view that will allow practitioners to be clear where each tool/technique applies. It will also identify gaps. Equally importantly, the project will enable the community to create coherent training courses and formal qualifications that will equip those dealing with digital objects of all kinds to preserve them in whatever way is appropriate and effective.

Complementing APARSEN and also founded in 2011 is SCIDIP-ES, SCIence Data Infrastructure for Preservation with its focus on Earth Science. ${ }^{20}$ This project will develop e-infrastructure services that will make it easier for institutions to maintain the understandability and usability of digital objects in the long term. The services address the threats identified by PARSE.Insight, using the techniques developed and proven by CASPAR.

Cumulatively, these outcomes provide a starting point for the infrastructure and tools the community needs. However, there is no guarantee that simply providing a set of services will be sufficient. Therefore, SCIDIP-ES is working with user communities to build up interest and a critical mass of users.

Summing up, the APA community provides a means for sharing the responsibility for digital preservation between institutions as well as a means to control the costs of digital preservation. These efforts are built upon community standards, OAIS in particular, as well as the new standards for audit and certification of digital repositories. ${ }^{21}$ The audit and certification process that will be based on these will allow funders to be assured that the repositories they fund are able to demonstrate good practice.

The APA illustrates the value of organizing digital preservation on an international scale, with a European beginning and the potential for global relevance, following a strategic roadmap supported by evidence.

\section{National Digital Preservation Coalitions}

Unlike the United States, where the Library of Congress took a clear lead, Europe saw the development of a number of bottom-

\footnotetext{
${ }^{20}$ The project website is available at www.scidip-es.eu (last accessed 04-24-2012).

${ }^{21}$ See http://www.trusteddigitalrepository.eu (last accessed 06-05-2012).
} 
up national digital preservation coalitions, established by libraries, archives, and research institutions that became aware of a joint interest in dealing with digital collections. The first national enabling organization was the Digital Preservation Coalition (DPC, UK and Ireland, established 2001), which broke new ground with its Mind the Gap report (2006), a first attempt at putting the special requirements of digital objects in a national organizational context. In 2003, the creation of the DPC was followed by the founding of nestor in Germany. Both coalitions have a broad aim to foster awareness of the issues, promote collaboration in digital preservation and, especially, develop and share knowledge. nestor's Handbuch-Eine kleine Enzyklopädie der digitalen Langzeitarchivierung has proven to be a valuable instrument. ${ }^{22}$ The DPC has evolved into an active advocate for digital preservation issues.

The Netherlands Digital Preservation Coalition (NCDD) was established in 2008. The NCDD took its starting point from earlier research (e.g., by the UK DPC) indicating that digital preservation is an issue that cannot successfully be addressed by any one organization, sector or even country. The NCDD drafted a rather ambitious mission "to establish a national infrastructure for providing long-term access to digital objects in the public domain." 23 This infrastructure is broadly understood to include hardware, software, requirements, policy, manpower, knowledge, and money. To lay the groundwork for such an infrastructure, the NCDD carried out its own digital preservation survey in $2009 .^{24}$ As of 2011, two working groups were actively researching possibilities for sharing storage space and for providing preservation services for the entire public domain. The working group reports are expected in 2012 and may signal a move to more intensive collaboration.

Meanwhile, a number of notable initiatives have been taken within sub-sections of the Coalition ${ }^{25}$ to facilitate the fulfillment of the requirements of this essay. In an attempt to bring about alignment with record producers, the National Archives have established a voluntary shared e-Depot service where non-current records that are still in the custody of government agencies are managed and preserved by the National Archives long before the

\footnotetext{
${ }^{22}$ See nestor's Handbuch: http://nestor.sub.uni-goettingen.de/handbuch/ (last accessed 04-24-2012).

${ }^{23}$ See NCDD: http://www.ncdd.nl/en/index.php (last accessed 04-24-2012).

${ }^{24} \mathrm{NCDD}$, A future for our digital memory,.

${ }^{25}$ For more information about the different alliances within the NCDD network, see http://www.ncdd.nl/en/over-organisatie.php (last accessed 04-24-2012).
} 
Archives take legal custody. In order to make the plan work, the National Archives had to lower its rather high metadata standards, thereby fulfilling the requirement to maximize commonality. ${ }^{26}$

Choices made at an early stage by the Dutch National Library, Koninklijke Bibliotheek, also reflect clear digital thinking: a digital repository that was developed for the national deposit collection was opened up to international publishers, because international publications really have no national base and the $\mathrm{KB}$ considered it highly unlikely that they would deposit their digital publications in every single country where they are sold. In this way, the KB maximized one of digital objects' key benefits: that ownership is no longer a precondition for access. Long-term preservation in just a few places can serve the world.

Nevertheless, as elsewhere, the Dutch landscape still has a lot of features of the analog age that need to be addressed. Examples are social media and other born-digital content, which still elude collection patterns, and new composite objects such as enhanced publications and websites.

\section{The International Internet Preservation Consortium (IIPC)}

The Internet is a truly global information space where much is published that eludes or exceeds traditional collection profiles and preservation regimes. It is mostly national and university libraries that have taken on the task of preserving web content, and in 2003, eleven national libraries joined forces with the Internet Archive (US) to establish the International Internet Preservation Consortium (IIPC). ${ }^{27}$ The IIPC's aim is "to enable the collection, preservation and long-term access of a rich body of Internet content from around the world."

The IIPC is a lightly-governed network organization that requires little more of its members than active engagement in the mission of the organization. The IIPC is increasingly referred to as one of the most successful collaborative initiatives in the digital preservation field. The IIPC has developed tools for web archiving, and, more importantly, the network has brokered joint initiatives to harvest online information about major (international) events, e.g., the 2008 Olympic Games and the 2011 Arab Spring. ${ }^{28}$

\footnotetext{
${ }^{26}$ Presentation by Ruud Yap to the Tallinn Digital Deposit Conference, 15

November 2011, see http://www.ncdd.nl/blog/?p=549 (last accessed 04-24-2012).

${ }^{27}$ See IIPC: http://netpreserve.org/about/index.php (last accessed 04-24-2012).

${ }^{28}$ See, e.g., presentations at the 2011 General Assembly at

http://netpreserve.org/events/2011GA.php (last accessed 04-24-2012).
} 


\section{Open Planets Foundation (OPF) and PrestoCentre}

As mentioned above, the European Union has been actively funding digital preservation research projects that bring together heritage communities from across Europe. As in the case of NDIIPP, however, the need for a more sustainable effort was felt in due course.

The Planets project ${ }^{29}$ developed digital preservation tools for the library and archives community, whereas PrestoPrime ${ }^{30}$ addressed similar issues in the audiovisual domain. When the projects ended, a number of project participants took the initiative to establish ongoing organizations to ensure maintenance and further development of the tools and expertise, resulting in the Open Planets Foundation $(\mathrm{OPF})^{31}$ and PrestoCentre. ${ }^{32}$ These initiatives are funded by the members. The ultimate success of these initiatives will inform the future of organizational alignment.

\section{MetaArchive and LOCKSS}

This case study shifts the focus from enabling organizations to collaborative initiatives in which the burden of preserving collections of digital content is shared by a number of organizations. The MetaArchive Cooperative ${ }^{33}$ and the LOCKSS Alliance $^{34}$ have each implemented digital preservation networks that adhere to the above requirements using distributed approaches.

The LOCKSS Alliance, MetaArchive Cooperative, and other similar distributed digital preservation (DDP) organizations have arisen in recent years as collaborative efforts between existing cultural memory institutions (libraries, archives, etc.). They intentionally establish affordable means for digital content to survive over the long periods of time in which such cultural memory institutions are accustomed to operating. ${ }^{35}$

The LOCKSS Alliance was established near the end of the 20th century to preserve electronic journal content. LOCKSS was

\footnotetext{
${ }^{29}$ See Planets: http://sourceforge.net/projects/planets-suite/ (last accessed 07-122012)

${ }^{30}$ See PrestoPrime: http://www.prestoprime.org/ (last accessed 04-24-2012).

${ }^{31}$ See OPF: http://www.openplanetsfoundation.org/ (last accessed 04-24-2012).

${ }^{32}$ See PrestoCentre: http://www.prestocentre.org/ (last accessed 04-24-2012).

${ }^{33}$ See MetaArchive: http://metaarchive.org (last accessed 04-24-2012).

${ }^{34}$ See LOCKSS: http://lockss.org (last accessed 04-24-2012).

${ }^{35}$ For more information about the distributed approach to digital preservation, see $A$ Guide to Distributed Digital Preservation. K. Skinner and M. Schultz, Eds. (Atlanta, GA: Educopia Institute, 2010), http://www.metaarchive.org/GDDP (last accessed 04-24-2012).
} 
established specifically to recreate in the digital realm the capability that libraries had historically possessed to preserve serial publications through distributed collecting strategies. This capability was difficult or impossible to implement in the digital realm because electronic serial publishers have increasingly tended to provide libraries with access to online serial content rather than actually transmitting the content to the libraries.

The LOCKSS software was developed at Stanford University in order to enable libraries to once again affordably maintain and manage journal content within their own infrastructures without ceding control of this important category of scholarly content to large publishing conglomerates. The software operates as a peerto-peer ( $\mathrm{P} 2 \mathrm{P})$ network for preservation purposes, and provides a variety of internal authenticity and integrity checking mechanisms for subscribed electronic journal content stored in the network.

The LOCKSS Alliance is an organizational framework created to coordinate usage of the LOCKSS software by libraries for these purposes. Today the LOCKSS Alliance includes hundreds of libraries around the world, acting together to preserve electronic journal content to which they subscribe.

The MetaArchive Cooperative was established in 2004 to preserve digital archives developed at local cultural memory institutions. MetaArchive was one of the first National Digital Information Infrastructure and Preservation Program (NDIIPP) projects, and was one of the founding members of the National Digital Stewardship Alliance (NDSA) in 2010. The organization is structured as a cooperative of libraries and archives operated jointly for mutual benefit through distributed digital preservation of member collections. MetaArchive used the LOCKSS software to create a separate peer-to-peer network for digital archives. Much like the LOCKSS network, MetaArchive has internal automated mechanisms for content integrity checks and monitoring. The MetaArchive Cooperative has layered a variety of additional digital curation tools onto the underlying LOCKSS software to provide additional curation and reporting capabilities for collections reposited in the network. As of this writing, the cooperative encompasses more than fifty institutions in four countries on two continents.

Variations in the basic DDP P2P model provided by LOCKSS have been implemented by several organizations. Thus far, apart from the MetaArchive Cooperative, two groups, Data- 
PASS and LuKII, ${ }^{36}$ have designed their private preservation networks in a similar manner. Like MetaArchive, each of these networks runs as an independent entity, organizationally distinct from the LOCKSS Alliance. A number of other DDP networks for digital archives have been created which depend upon the LOCKSS team at the Stanford University Libraries to run their core technical infrastructure (examples include the Alabama Digital Preservation Network (ADPN), the Canadian COPPUL project, and the PeDALS project in Arizona.) $)^{37}$ All of these projects have collectively been referred to as "Private LOCKSS Networks" (or PLNs), meaning networks that use the LOCKSS software to enable particular groups of institutions to preserve targeted bodies of content. To date, there are almost a dozen PLNs successfully preserving content on behalf of their constituent members.

The three common functions of all DDP networks, LOCKSSbased or otherwise (as this phrase is understood here) that distinguish them from other preservation approaches are as follows:

- Replication of content;

- Distribution of these replicated copies to distinct geographical locations; and

- Network organization to connect these replicated copies through routine operations, including checksum comparisons and repair activities.

In the DDP approach, long-term commitment is achieved by the collective actions of the entire consortium of collaborating institutions. In the case of MetaArchive, individual institutions may come and go, but the network survives. This attribute intentionally emulates the sustainability of the Internet itself, in which no single node or group of nodes is required to continue functioning for the network as a whole to continue functioning. It is important to note that, while participating in the network, institutions are bound by a Cooperative Charter $^{38}$ and a

\footnotetext{
${ }^{36}$ See DataPASS: http://www.data-pass.org/ and LuKII: http://www.lukii.huberlin.de/ (both last accessed 07-12-2012).

${ }^{37}$ See ADPNet: http://adpn.org; COPPUL: http://www.coppul.ca/pln.html; PeDALS: http://www.pedalspreservation.org/ (all last accessed 04-24-2012).

${ }^{38}$ See the MetaArchive Cooperative Charter: http://www.metaarchive.org/public/resources/charter_member/2011_MetaArchive Charter.pdf (last accessed 04-24-2012).
} 
Membership Agreement ${ }^{39}$ outlining their rights and responsibilities.

By structuring the organization as a collaborative effort, PLNs are able to achieve scale in technical expertise and infrastructure for digital preservation. Whereas any single cultural memory organization will typically lack the resources for deep investments in such expertise and infrastructure, a cooperative of many individual institutions can share the burden of such investments and thereby make it affordable.

DDP networks such as MetaArchive possess another powerful element of sustainability in that all members of such networks simultaneously act as producers, archives and consumers. Each institutional member of the network acts as a producer when creating digital content locally, often through digitization programs. Each institutional node in the network functions as an archive for such content, with groups of institutional nodes acting in concert to preserve content in multiple locations that are securely maintained.

By providing a functioning DDP network that is affordable and practical today, MetaArchive has enabled more than 50 institutions to begin digital preservation activities now, not in some distant hypothetical future.

There are relatively slight but nevertheless significant differences between the original LOCKSS e-journal preservation network and PLNs. First, the genre distinction is significant. While PLNs are typically aimed at preservation of content produced in and owned by the institutional member sites (especially locally digitized archives), LOCKSS is aimed at preservation of commercially purchased electronic journal content. This distinction means that institutional members do not function in the role of content producers. Second, the nature of interorganizational agreements in the LOCKSS Alliance is different from the contractual agreements that link the PLN's members. For example, LOCKSS Alliance members are more loosely coupled than MetaArchive members, with no contractual obligations to continue maintaining their respective DDP nodes. This slightly changes the circumstances of the first requirement above, in that there is a less specific set of commitments in place to ensure the long-term preservation of content. The LOCKSS Alliance counts on the inborn motivation of libraries and other members to

\footnotetext{
${ }^{39}$ See the MetaArchive Membership Agreement: http://www.metaarchive.org/public/resources/charter_member/2011_Membership Agreement.pdf (last accessed 04-24-2012).
} 
preserve the content that they have purchased at great institutional expense. This motivation means that members have a vested interest (albeit not a contractual one) in preserving one others' content.

\section{Chronopolis: A Federated Grid Solution}

In the US, the Chronopolis network ${ }^{40}$ has been developed by the San Diego Supercomputer Center (SCSC), the UC San Diego Libraries (UCSDL), the National Center for Atmospheric Research (NCAR) and the University of Maryland's Institute for Advanced Computer Studies (UMIACS). Integrating digital library, data grid, and persistent archive technologies, Chronopolis has created a trusted environment that spans academic institutions and research projects, with the goal of long-term digital preservation.

Chronopolis provides replication (three copies), however, format obsolescence is considered to be the responsibility of the data provider.

\section{Other Types of Solutions}

\section{A National Facility}

In Scandinavia, both Denmark and Finland have adopted national approaches to digital preservation. Finland is planning the establishment of a national digital preservation facility in the context of the Finnish National Digital Library. ${ }^{41}$ An in-depth report quantifying the benefits of such a centralized approach was published in September 2010. ${ }^{42}$ It must be noted, however, that this central facility is intended to serve only museums, archives and libraries within the purview of the Ministry of Education and Culture. Notably scientific digital data are not included in the plans. As of early 2012, implementation of the plans has not yet begun.

\footnotetext{
${ }^{40}$ See Chronopolis: https://chronopolis.sdsc.edu/about/index.html; for an overview, see David Minor, Don Sutton, Ardys Kozbial, Brad Westbrook, Michael Burek and Michael Smorul, "Chronopolis Digital Preservation Network," International Journal of Curation, Vol. 5, Issue 1 (2010), http://www.ijdc.net/index.php/ijdc/article/view/150 (both last accessed 04-242012).

${ }^{41}$ See Finish National Digital Library: http://www.kdk.fi/en (last accessed 04-242012).

${ }^{42}$ See the National Digital Library Initiative Long-term Preservation Project, Final Report, v. 1.0, http://www.kdk.fi/images/stories/LTP_Final_Report_v_1_1.pdf (last accessed 04-24-2012).
} 
In Denmark three national institutions (the Royal Library, the State Archives and the State and University Library at Aarhus) are presently implementing a National Danish Bit Repository (Bitmagasin $^{43}$ where multiple copies of digital objects can be kept with the express aim of facilitating long-term preservation. Interestingly, the three "pillars" of the repository have different digital preservation hardware, allowing for the content to be replicated and stored truly independently. In time, it is expected that more institutions will start making use of the repository, whereby they can choose between the different "pillars."

In the Netherlands, major archives have joined forces to propose a plan for a joint shared services center for the archives at all three tiers of government: national, provincial, and municipal. ${ }^{44}$ The plan was presented in June 2010, but as of early 2012, implementation is still awaiting government approval and funding.

\section{Single-Repository Solutions}

Libraries' concerns that licensed digital content might at some point in time no longer be accessible to them led not only to solutions with distributed governance such as LOCKSS and MetaArchive, but also to more centralized solutions whereby one institution acts as a steward for third-party content.

Centralized solutions include Portico ${ }^{45}$ (US) and the Dutch KB's e-Depot, ${ }^{46}$ both of which include archiving agreements with major international publishers to ensure continued access for libraries in case the publishers' service breaks down.

The HathiTrust Digital Library, ${ }^{47}$ which archives digitized collections from libraries, is perhaps an intermediate solution between a distributed network and a centralized approach: it works with a single repository, but its governance is shared by the participating institutions. ${ }^{48}$

\footnotetext{
${ }^{43}$ See Bitmagasia: http://digitalbevaring.dk/det-nationale-bitmagasin/ (Danish; but Google translate will help); https://sbforge.org/display/BITMAG/The+Bit+Repository+project;jsessionid=CD 5EDF2756B2505530D5564E5E1D93E4 includes information in English, especially of a more technical nature (last accessed 04-24-2012).

${ }^{44}$ See http://www.ncdd.nl/en/artikel.php?id=83 (last accessed 16-05-2012)

${ }^{45}$ See PORTICO: http://www.portico.org/digital-preservation/ (last accessed 04-242012)

${ }^{46}$ See e-Depot: http://www.kb.nl/hrd/dd/index-en.html (last accessed 04-24-2012).

${ }^{47}$ See HathiTrust: http://www.hathitrust.org/about (last accessed 04-24-2012).

${ }^{48}$ Originally, governance was restricted to the founding partners; as of 2012, the Board of Governors also includes other participating institutions.
} 


\section{DuraCloud}

DuraSpace is a not-for-profit organization that has recently launched a cloud-based storage service, DuraCloud, ${ }^{49}$ with some digital preservation services, such as "health check-ups." Cloud storage is flexible and scalable, and the subscription models can be attractive. However, institutions do lose some control over their collections which raises privacy and copyright issues. DuraCloud addresses some of these issues by allowing customers to choose where their content is stored.

\section{Progress to Date}

Reviewing the case studies in this essay, it is clear that in the past ten years, memory institutions have made substantial progress in meeting the challenge of their digital collections.

The requirements listed at the beginning of this essay, as well as the experiences of the institutions described above, clearly show that initiatives to promote digital preservation and long-term access benefit greatly from a cooperative approach. Very often, the reasons to seek cooperation will be economic. Many new challenges of the digital world can only be faced by the community as a whole: a new division of labor, agreements about succession planning, technical interoperability.

But collaboration does not come easy. The stakeholders in the digital preservation chain have different backgrounds, different technical systems, and often speak different languages. Enabling organizations, such as those described in this essay: NDIIPP, APA, OPF, PrestoCentre, and the national coalitions (DPC, nestor, NCDD), play a mediating role. All of them raise awareness of the digital preservation issues, make the case with funders, bring together stakeholders with different backgrounds and facilitate constructive discussions between them to leverage their commonalities. This is vital work, but it is also challenging and time-consuming. The availability of funding, as in the case of NDIIPP, can help bring stakeholders together. In other cases (APA, OPF), active participation in research and development helps avoid the possible pitfalls of voluntary membership organizations: that stakeholders may be reticent to commit and years go by discussing good intentions without any real practical results. Whereas in the European context international alliances have been instrumental in procuring project money from the European Union, national coalitions may be better positioned to

\footnotetext{
${ }^{49}$ See DuraCloud: http://www.duracloud.org/tour (last accessed 04-24-2012).
} 
influence the legal agendas of lower tiers of governments and procure structural funding for long-term repositories.

It can be argued that enabling organizations are temporary phenomena to facilitate the transition from an analog to a digital world. Indeed, William Kilbride, Director of the UK DPC, has been known to tell conferences that the DPC's mission must be to make itself redundant - when digital preservation will have become "business as usual" and the requirements are fulfilled. ${ }^{50}$

A look at the alliances that share responsibility for digital preservation finds considerable progress, especially in Western countries. The United States has spawned quite a number of distributed preservation networks, such as LOCKSS, MetaArchive, HathiTrust, Chronopolis, and others. These initiatives have been particularly useful in enabling institutions to replicate their content and form communities.

File format obsolescence is one of the core challenges of digital preservation and differing approaches and perspectives have emerged. For example, LOCKSS Director David Rosenthal has argued that format obsolescence is much less of a problem than Jeff Rothenberg assumed in $1995 .^{51}$ Rosenthal asserts that preservation actions such as migration are unnecessary for widely accepted file formats from 1995 until the present, as the IT industry is expected to guarantee backwards compatibility. ${ }^{52}$ Should accessibility problems arise anyway, Rosenthal argues, we should deal with them at the access end, not at ingest. Portico and the KB do not put their trust in this philosophy, and the Danish National Archives take what they see as a more active approach to preservation planning: they migrate every object they receive to standardized formats (PDF/A) for reasons of cost reduction and manageability of the collections (while preserving the original as a back-up). ${ }^{53}$ Results over time will demonstrate the effectiveness of

\footnotetext{
${ }^{50}$ A.o. his presentation before 2010 IS\&T conference in The Hague, "Digital Preservation in Byte-Sized Chunks: Good Practice, Best Practice and Why We Should Be Careful What We Wish For" in Archiving 2010, available from http://www.imaging.org/IST/store/physpub.cfm?seriesid=28\&pubid=941 (last accessed 04-24-2012).

${ }^{51}$ Jeff Rothenberg, "Ensuring the longevity of digital documents," 1999 update of 1995 article, http://www.clir.org/pubs/archives/ensuring.pdf (last accessed 04-242012).

${ }^{52}$ David S. Rosenthal, "How are we ensuring the longevity of digital documents?," Presentation to CNI Plenary Session, 7-9 April 2009, http://vimeo.com/5407401 (last accessed 04-24-2012).

${ }^{53}$ See Alex Thirifays, Anders Bo Nielsen and Barbara Dokkedal, "Evaluation of a Large Migration Project," iPRES2011 Proceedings, pp. 24ff. The proceedings
} 
these approaches. It is the case that collaborative (distributed) initiatives are rarer in Europe than they are in the US, possibly leaving smaller institutions more vulnerable than those that have joined distributed networks.

\section{Opportunities for Alignment}

Looking ahead at where the community might be in five years, there are two main areas where alignment provides beneficial results: furthering the geographic spread of the lessons learned from case studies as just described and as documented in emerging good practice, and working together to extend the scope of content preserved by sustainable digital preservation programs.

Geographically, community efforts to date have largely covered only portions of the world (mainly Europe, North America, Australia, and New Zealand). This is partly because other parts of the world are at a different stage of development. On the other hand, the digital environment offers new possibilities to reach across borders and collaborate to save content. Issues like these will be addressed at the 2012 UNESCO Conference (September 26-28, Vancouver, Canada ${ }^{54}$ ), but as they are closely intertwined with general issues of development, it is difficult to estimate where we should or could be in five years.

As the case studies show, the type of content currently preserved in collaborative (central or distributed) preservation facilities is generally of the more "manageable" kind, in the sense that a) the producers are known, within reach of archiving institutions, and generally well organized (libraries, publishers), and $b$ ) the types of objects preserved are often relatively simple and certainly renderable (PDF, jpeg, tiff, etc.). ${ }^{55}$ However, vast amounts of data on the Internet are, at present, not being collected and never become part of any type of chain of preservation, because they do not fit into traditional collection profiles. The transformation from analog to digital practice is in progress (Requirement 6); effective interaction between producers, stewards, and users is often lacking (Requirement 3), and a long-

were published in 2012 at http://ipres2011.sg/conference-procedings (last accessed 07-12-2012).

${ }^{54}$ See the UNESCO calendar for the event listing:

http://www.unesco.org/new/en/communication-and-information/events/calendarof-events/events-websites/the-memory-of-the-world-in-the-digital-agedigitization-and-preservation/ (last accessed 04-24-2012).

55 Admittedly, scientific e-journals increasingly include research data of a much more complicated kind. It is unclear how well the present arrangements are suited to deal with these. 
term commitment to preservation is also lacking (Requirement 1). Categories of data that are particularly threatened in this way include (but are not limited to):

- Scientific data held by individual researchers or research groups;

- Social media (blogs, Facebook, etc.);

- Audiovisual objects produced by individuals then published on the internet; and

- Websites (international websites and countries lacking domain harvesting). ${ }^{56}$

In five years' time, the community may have made progress on addressing these issues. Alignment will require international and cross-domain action at a global scale.

The shift from the analog paradigm to the digital paradigm includes the shift from local/regional information spaces to a global information space and the shift from separate library, archive, and scientific information spaces to a globally linked information space. This paradigm shift is not yet sufficiently reflected in our institutions or our infrastructures. Parts of the einfrastructure are in place or being developed, as demonstrated by the case studies in this essay, but too much information continues to elude existing frameworks and it is urgent that we find ways to select, collect, and preserve it before it is lost.

\section{Next Steps}

While local and regional collaborative initiatives are helping individual institutions cope with the digital challenge, the issues of global inclusion and of born-digital content that is presently eluding collection frameworks are indeed so global in nature that national and regional efforts cannot deal with them. These issues should be elevated to an international level.

Laura Campbell (Library of Congress) has encouraged the establishment of an international preservation body with a focus on policy, perhaps assisted by an advisory expert group to identify what categories of digital objects are most at risk. ${ }^{57}$ The body

\footnotetext{
${ }^{56}$ In addition scientific and commercial data with specialised syntax and semantics are in danger of becoming unusable after quite a short time. In particular re-use in new contexts would become increasingly impossible without capturing sufficient Representation Information, as outlined in Giaretta, However, as this is more of a technical issue, it is not discussed further in this essay.

${ }^{57}$ Laura Campbell, see note 2 above.
} 
could promote an international notion of collection, work on standards and tools, and perhaps maintain a common index of preserved materials. This idea merits further exploration. One opportunity will be the UNESCO Conference "The Memory of the World in the Digital Age: Digitization and Preservation" (26-28 September 2012). In addition, the iPres Conference offers an annual opportunity to address digital preservation challenges and opportunities. The enabling organizations described in this essay should continue to contribute to international organizational alignment. $^{58}$

\section{References}

Anderson, Martha, "Evolving a Network of Networks," The International Journal of Digital Curation, Issue 1, vol 3, 2008.

www.ijdc.net/index.php/ijdc/article/download/59/38 (last accessed 04-24-2012).

A Guide to Distributed Digital Preservation. K. Skinner and M. Schultz, Eds. (Atlanta, GA: Educopia Institute, 2010), http://www.metaarchive.org/GDDP (last accessed 04-242012).

Mind the Gap: Assessing Digital Preservation Needs in the UK, DPC, 2006, http://www.dpconline.org/advocacy/mindthe-gap (last accessed 04-24-2012).

NCDD (Netherlands Coalition for Digital Preservation), A Future for our Digital Memory: permanent access to information in the Netherlands, English summary, http://www.ncdd.nl/en/documents/Englishsummary 000. pdf (last accessed 04-24-2012).

New Roles for New Times: Digital Curation for Preservation, by Tyler Walters and Katherine Skinner, Report prepared for the Association of Research Libraries, March 2011, http://www.arl.org/bm doc/nrnt_digital_curation17mar11 .pdf (last accessed 06-05-2012).

Preserving Our Digital Heritage: The National Digital Information Infrastructure and Preservation Program

\footnotetext{
${ }^{58} \mathrm{http}$ ///www.unesco.org/new/en/communication-and-information/events/calendarof-events/events-websites/the-memory-of-the-world-in-the-digital-agedigitization-and-preservation/
} 
2012 Report.

http://www.digitalpreservation.gov/documents/NDIIPP20 10Report Post.pdf (last accessed 05-17-2012).

Rothenberg, Jeff, "Ensuring the longevity of digital documents," 1999 update of 1995 article, http://www.clir.org/pubs/archives/ensuring.pdf (last accessed 04-24-2012).

Rosenthal, David S., "How are we ensuring the longevity of digital documents?," Presentation to CNI Plenary Session, 7-9 April 2009, http://vimeo.com/5407401 (last accessed 0424-2012).

Sustaining Economics for a Digital Planet: Ensuring Long-term Access to Digital Information, Final Report of the Blue Ribbon Task Force on Sustainable Digital Preservation and Access, February 2010, http://brtf.sdsc.edu/ (last accessed 04-24-2012).

Zorich, Diane; Gunter Waibel, Ricky Erway: Beyond the Silos of the LAMs: Collaboration among Libraries, Archives and Museums, OCLC, 2008;

http://www.oclc.org/research/publications/library/2008/20 08-05.pdf (last accessed 07-12-2012). 